\title{
Harnessing energy: an alternative way to view the management of highway assets
}

David Williams PhD, MSc, BSc (Hons), MTPS

Department of Geography, University of the West of England, Bristol, UK

(david23.william@uwe.ac.uk) (Orcid:0000-0002-9272-3622)

\begin{abstract}
Highway networks form the arteries of a country, allowing goods and people to flow, thereby creating the heartbeat of the economy. In the UK, the level of funding available to continue to maintain this network to a high standard is set to reduce dramatically. This paper explores the potential for energy to be harnessed from the forces that the network is exposed to everyday, solar, wind, rainwater and kinetic energy from vehicles, to provide additional funding to local authorities while also providing a potential solution to the trilemma of energy issues facing the UK: providing cheap, clean and renewable energy. The paper includes a set of recommendations follow to bring this technology from the prototype phase to mass roll-out.
\end{abstract}

\section{Introduction}

The first two decades of the twenty-first century have seen unprecedented developments in technology in terms of computing, information and mobile technology. Yet these advances have not reduced the demand for people and goods to travel. There has been no significant change from the travel patterns of the late twentieth century, with towns and cities worldwide still having weekday peaks in travel in both the morning and evening, as people journey to and from work. Levels of private vehicle use have increased dramatically across the world between 2005 and 2015 (Oica, 2017), making this the predominant mode of travel in many countries for these journeys, particularly for commuting. Since 2005, Asia (excluding Japan and South Korea), the Middle East and Australia have seen a 141\% increase in vehicles; Central America, Latin America and the former Soviet bloc countries have seen increases of around $60 \%$; Africa, 35\%; and Europe, Japan, South Korea and North America, between 5 and $10 \%$ (Oica, 2017). This increase in traffic worldwide adds pressure to the existing highway infrastructure assets and how they are managed.

A nation's highway infrastructure forms the arteries of the country, allowing the everyday flow of goods and people and creating the heartbeat of the economy. The highway network's importance, alongside other infrastructure assets, was highlighted in former president of the USA Barack Obama's 'You Didn't Build That' speech in 2012, which focused on the benefits all businesses in the USA had received from state and utility company assets that enabled their growth and subsequent success (Cohen, 2012). Innovation and investment in infrastructure are essential to ensure a country's economy thrives.

Unlike the information technology sector, there has been little or no radical change to the technologies used to create the carriageway pavements of highways since the end of the twentieth century, with concrete and asphalt being the two primary materials used worldwide. Highway assets have become an accepted part of the physical environment, and to most people, they seem mundane and can often be invisible to users until they fail (Graham, 2010). The effective management of highway assets to prevent their failure and the impact this would have on the economic and social infrastructures that rely on them. While concrete and asphalt are hard wearing, the impact of the weather means that they are prone to damage, particularly in countries such as the UK where the surface of the carriageway is subjected to both high and low temperatures throughout the year. It is therefore essential for governments and asset-managing organisations to optimise the performance of their maintenance regimes to ensure their assets perform as expected.

This paper is designed to provide a new way of thinking about existing highway assets, how their maintenance is funded and what they provide to society in addition to enabling travel. As such it is a think piece and therefore does not include any data analysis or a case study. The paper focuses on the UK highway system and discusses the existing technology that exists to generate energy from highway infrastructure, whether this can be integrated together to provide a more stable supply of energy and whether it is possible to store and use the energy produced. The paper concludes by providing recommendations of the steps required to trial and test this technology.

\section{UK highway asset management regime}

In the UK, highway assets are managed by two types of organisation. Highways that are defined as strategic roads, motorways and significant A roads are managed by government quangos, Highways England and Highways Scotland, with all roads in Northern Ireland managed by the Department for Infrastructure Roads. This paper focuses on the remaining $87 \%$ of the UK's highway network that is managed and maintained by local authorities (DfT, 2016), who act as guardians of the highway network.

Although the materials used to create the carriageway pavement have not changed significantly in the past 20 years, the way local authorities manage highway maintenance has. This has been through the adoption of an asset management approach rather 
than fixing the worst first. This transition has been supported by the Department for Transport (DfT), through the incentive of additional funding to local authorities for the introduction of the Highways Maintenance Efficiency Programme (HMEP) (CIC, 2013), which was developed by the DfT to promote efficient and effective working practices at the local authority level. As of 2016, 98\% of local authorities in the UK were participating in HMEP (HMEP, 2017). The asset management approach means that many authorities are prioritising the maintenance of assets to prevent them from falling into a state of disrepair, while managing, where possible with the remaining budget, to bring the worst surfaces up to a decent standard. This approach can be challenging politically with councillors pressured by voters to fix the worst highway assets under their control.

Asset management is defined by ISO 55000 as 'the coordinated activity of an organization to realize value from assets' (Re Cecconi et al., 2016). The problem with this definition in relation to highway infrastructure assets is that the return they provide is not recouped by the highway authority, and the value they provide instead contributes to the wider society and the economy (Srinivasan and Parlikad, 2017). While national taxes ultimately pay for the maintenance of roads in the UK, so it is understandable that those who pay should benefit, this does mean that there are very few opportunities for local authorities to recoup money from their highway assets to pay for maintenance and other services they provide.

\section{Financial pressures on local authorities}

Local authorities in the UK are facing significant financial pressures due to the reduction of central government funding they receive. This means that by 2020 , there will be a $£ 5.8$ billion shortfall in local authority financing available to maintain all services provided at 2015/16 levels (Ingram, 2017). This shortfall includes the funding for highway maintenance, which is not ring fenced like other services such as adult social care (Butler, 2013), and this will have a significant impact on local authorities' ability to maintain the existing carriageways to a high standard.

Local authorities in the UK do not currently have any ability to charge people to use their highway network. With the exception of London, there has been no move to introduce road user charging in the UK in the past 50 years (Ryley, 2010). Local councils have received significant criticism for generating revenue from parking charges (BBC, 2017), and opportunities to introduce charging are unlikely to come forward in the next decade. In most countries, highway infrastructure provision has been either provided or funded by the state. How maintenance of existing infrastructure is funded in the twenty-first century requires a radical rethink of what this infrastructure can provide for society in terms of both movement of goods and people and energy production.

\section{New ways of thinking about highway assets}

This paper proposes the idea that if implemented correctly, highway assets can be utilised to generate cheap, renewable energy in a way that creates an incentive to the UK government and local authorities to maintain the infrastructure to a high standard. Highway assets are subjected to different forces everyday: solar radiation, water, wind and kinetic energies from vehicles passing over the carriageway surface and structures. Separately, each of these actions produces small amounts of energy that is not cost effective to capture. If, however, this energy could be combined together from multiple sources across the whole of a network, there is the potential to generate a vast amount of electricity. This electricity can be used to maintain the surface temperature of the carriageway, thereby reducing maintenance costs, and provide additional energy to feed back into the grid. Connecting a set of microgeneration systems across the highway network offers an opportunity to harness some of this energy. Diversifying the sources of energy production would also allow for issues that are used to criticise renewables, as energy would be created in almost all weather conditions, as people would be generating small amounts of energy from a number of different sources. The production of energy from the highway network would reduce the farmland required for solar farms and the criticism of aesthetic impacts of solar and wind farms (Rodrigues et al., 2010).

\section{Providing energy security}

In addition to the issues of maintaining highways, harnessing this energy has the potential to benefit the UK economy by helping the UK government tackle the 'trilemma' of energy challenges identified in their Building Our Industrial Strategy green paper: meeting climate change targets, guaranteeing security of supply and minimising energy costs (HM Government, 2017). At present, the UK is heavily reliant on energy and fuel from areas of the world that are politically or environmentally unstable, with $45 \%$ of the energy needed coming from imports in 2015 (DECC, 2015). The UK government is investing significantly in nuclear power, as a means of delivering energy security, but this is costly, estimated to be up to $£ 37$ billion for a new nuclear power station at Hinckley Point (Jenkins, 2016). The company delivering the technology EDF Energy UK have struggled to deliver similar reactors on budget (Reuters, 2015) or on time (Vaughan, 2017). This paper recommends that government funding should be committed to trialling a range of alternative methods of energy production, such as harnessing energy from highways. Diversifying the range of energy sources should protect the country, should EDF Energy UK fail to deliver the level of energy predicted.

\section{Solving three problems at once}

By harnessing energy from the highways, the UK government would have the opportunity to solve three separate problems

- improve the level of funding available to local authorities for all services they provide

- create the means of maintaining the highway network to a high standard

- provide a secure energy supply that is cheap, renewable and clean. 
The next challenge is to understand what technology exists to harness this energy and how it can be captured, stored and utilised effectively.

\section{Energy harnessing technology}

There have been numerous schemes to harvest energy from the highway network trialled across the world, but as yet, none has gone into mass production. The reasons why these technologies have failed to be delivered are discussed in the following section. The following section provides an overview of the existing technologies.

\section{Solar energy}

One of the most widely publicised technologies within the field of solar energy harvesting was invented by the US crowd-funded organisation Solar Roadways. Solar Roadways have designed a system to harvest energy from the carriageway surface using textured glass solar panels. The designers were given a $\$ 100000$ grant from the US Department of Transportation in 2009 to build a prototype. This was followed in 2011 by a $\$ 750000$ grant to create a car park demonstration system (Solar Roadways, 2016). Issues relating to the uncertainty of how the materials would perform through constant use and wear and tear were highlighted during the prototype phase of the project. The major barrier to this technology is the cost of construction, \$56 trillion to replace the US highway network (Anthony, 2014), and the difficulty of rolling out across the highway network availability of raw materials required to construct tempered, self-cleaning glass (Biello, 2014). While the engineers behind Solar Roadways continue to trial and improve their technology, it is possible that low-tech solutions such as photovoltaic cells, discussed in the following, may be more suitable for mass production and rollout in the UK, particularly due to the cost of maintenance and replacement of infrastructure.

Other methods have been utilised to attempt to generate electricity from highway carriageway. Hasebe et al. (2006) designed a thermoelectric generator that produces energy through tubes under the carriageway surface that are heated by solar radiation and then cooled through water collected from a nearby watercourse. Electric power is then generated through the temperature difference between the hot and cold water. The hot and cold water is then used to maintain the carriageway surface temperature throughout the year reducing the temperature extremes that damage the surface, minimising the level of maintenance required (Hasebe et al., 2006). The primary limitation of Hasebe et al.'s (2006) approach is that the road would need to be close to an existing watercourse for the technology to be delivered. Reducing the impacts of extreme heating and cooling would provide significant savings to local authorities, as potholes formed by the surface breaking up due to extreme weather cost the UK government $£ 120$ million to fill (Sheehan, 2018). This funding could be used to maintain more of the network to a higher standard if the impacts of extreme temperatures were mitigated through this type of technology.

Zhou et al. (2013) found that in their tests, a solar road was $3-6^{\circ} \mathrm{C}$ lower than a normal road in the summer months, reducing the impact of high temperatures on the surface. In addition, Zhou et al. (2013) found that $14 \cdot 4 \%$ of solar radiation was captured through this approach. While this level of energy capture is not as high as standard photovoltaic cells, it still represents a significant level of energy capture across the highway network of an entire country. In 2017, Colas (2017) trialled their own photovoltaic highway surface in Normandy, France, and found that $20 \mathrm{~m}^{2}$ of tiles would be enough to power one house. Colas' photovoltaic tiles can also be laid directly onto existing carriageway pavements, reducing the need for significant highway reconstruction. This type of technology has also been trialled on a cycle path in the Netherlands. The study found that a $70 \mathrm{~m}$ cycle path could produce energy for one house (MacDonald, 2015).

Of the four methods of energy production from highway assets discussed in this paper, the street lighting market is the most mature with several products already available. The German company Scotia has created zero-emission street lamps that convert sunlight to street light by way of photovoltaic cells (Doward, 2016). This energy can be stored in batteries or fed back into the grid. To maximise energy generation, another company, Energy Environmental Technical Services (EETS), has included a wind turbine in addition to a photovoltaic cell that can help ensure that the unit generates power at night and during the winter (EETS, 2016).

\section{Wind power}

The average wind speed in the UK is $13 \mathrm{mph}(20 \cdot 9 \mathrm{kph})$, although this varies across the country with the highlands of Scotland windier than Cambridgeshire, for example (MacKay, 2009a). To maximise the benefits of wind power, windmills would need to be installed across the country. Tying this in to existing highway infrastructure would lessen the impact on the environment, both visual and land use, providing the means to generate energy within urban areas. This would help mitigate the criticism of this technology that currently exists.

Research has shown that hybrid energy street lighting is optimal in countries with weak grid systems (Al Badwawi et al., 2015; Guosheng et al., 2011). While the UK grid system is not weak in terms of energy availability, any means of reducing demand and possibly increasing supply would provide a benefit to the country's energy supply and thus help mitigate future rises in energy demand. Due to the availability of products, these would be as easy to install as conventional street lamps, albeit at a greater initial cost. Energy capture lighting columns offer significant potential benefits to local authorities as most residential streets in the UK have some form of street lighting. Keeping these lights on at night is a considerable cost to local authorities, estimating the cost to be around $£ 300$ million per year in 2016 (Doward, 2016). In addition to the cost, street lighting is a significant source of carbon dioxide emissions, the mitigation of which is one of the UK's trilemma of energy challenges (HM Government, 2017). It is estimated that if the 7 million street lights in the UK were converted to this technology, it could 
produce 4 TWh of energy a year, half the output of the Sizewell B nuclear power station (Doward, 2016).

\section{Rainwater harvesting}

Of all the forces that the highway network is exposed to water is the most prevalent. Between 1981 and 2010, it rained on average 133 times per year in England (Met Office, 2012), with higher levels of rain recorded in Scotland and Wales. At present, the management of this water and the impact it has on the road surface is a significant problem in highway maintenance terms, as water gets into gaps within the surface slowly breaking it down, forming potholes as the surface degrades. In addition to this, the issues of the water within the road surface freezing and thawing leads to significant issues in terms of maintenance. The movement of water through the drainage systems does, however, provide an opportunity to create energy.

To generate this energy, any new carriageway surface would need to include a sustainable urban drainage system (SuDS) or include a pervious highway surface. This allows the water to filter through into the drainage system rather than stay on the surface of the highway. Novo et al. (2013) found that the introduction of a SuDS helped filter the water of waste and impurities so that it could be used to produce energy through ground source heat pumps (GSHPs). GSHPs create energy in a similar way to the heating and cooling of the system discussed in the section headed 'Solar energy' except they used the energy of the ground rather than solar power. However, it is possible that the water from the drainage system could be used in conjunction with the pipes in the solar roads instead of installing a GSHP for the system to be incorporated successfully into the highway network.

A second approach for generating energy was adopted in Le Châble, Switzerland, in 1992. This involved the installation of hydroturbines within the existing sewage system. The scheme overcame issues of solid elements in the water and corrosion resistance through the use of stainless steel and ceramic coating of the turbine (Duflon, 2016). Designing this technology to sit within existing drainage systems would be incredibly challenging, but not insurmountable, although the turbines would have to be relatively small and less complex in comparison to the system in Le Châble.

\section{Kinetic energy}

The final potential energy source is harnessing energy from the movement of cars. Trial schemes for this technology have already been implemented in the UK, with the installation of 'sleeping policemen' in the carriageway that generate free kinetic energy. The panels are almost flush with the existing road surface and are pushed down as the car passes over it, reducing the need for additional energy from the car's engine to manoeuvre over the surface. This system sets a cog in motion to turn a motor that creates mechanical energy (Ilahi et al., 2013). In the UK, the units cost between $£ 20000$ and $£ 55000$ (at 2009 prices) depending on the size of the unit; with ten units generating a similar level of energy as one wind turbine (Phillips, 2009a). This technology was installed at the car park of Sainsbury in Gloucester in 2009 and produced enough power to run the tills of the store (Phillips, 2009b).

Alternative methods of energy generation using the movement of vehicles have also been trialled across the world. A piezoelectric energy system has recently been trialled in South Korea that generates energy as vehicles move along the road. This is gathered through cantilever beams that do not raise the road surface, so it can be integrated into an existing highway network, with the designers believing that this system has the potential to become a macro energy producer if the trials continue to be successful (Yewon et al., 2016). One of the issues is the difficulty in maintaining and replacing the parts if the system contains too many components that are unable to withstand the constant impact from vehicles, as the cost of purchasing and maintaining the network would be too prohibitive if delivered across the entire highway network. A far simpler system was designed by Mexican entrepreneur Macías Hernández that uses small ramps in the road that are pushed down that forces compressed air into a storage tank. This is fed into a turbine to generate electricity (Coxworth, 2013). This is a more low-tech approach, which, if mass produced, would be cheaper to construct and easier to maintain than the piezoelectric system. Again, this scheme has only been trialled rather than mass produced with the early results suggesting that the technology would generate energy. To maximise the benefits of this technology, the components need to be cheap to install, purchase, use, maintain and eventually replace, particularly if rolled out on a large scale.

\section{Challenges of delivering energy-harnessing technologies}

The challenge for many of these energy capture technologies is that they as yet have rarely made it past the trial phase, possibly due to the cost of implementation and payback period in terms of the energy produced and savings made. The challenge with solar energy is the uncertainty of the level of energy that will be produced due to the prevailing weather conditions, particularly in Northern Europe and North America. To invest in this technology alone would not make sense from a financial perspective at this point in time; however, solar energy could be incorporated into a larger approach that adopts other energy-generating schemes, thereby making the level of energy produced overall greater and the payback period shorter.

The second barrier to investment in new technology is the cost of the units and an agreement between local authorities and energy companies to produce energy in this way. This could be achieved through the development of consortia between the parties, which set out agreed inputs, both financial and physical assets and an agreement for profit-sharing the returns on the energy produced. Many highway assets have existing cabling for energy to properties and street lighting running under highway surfaces. The consortia could work together to identify the best approach for feeding the electricity generated to be either fed back into the grid or stored in batteries so the energy could be used locally. For technologies such as lighting columns that generate energy from solar or solar and wind sources, it would benefit local authorities 
to work together to bulk purchase these items, reducing the cost per item. This procurement strategy could then be utilised once other energy harnessing technologies come to market.

\section{Hybrid renewable energy systems}

One of the main reasons why none of the four technologies discussed has been adopted by local authorities at the present time is due to the cost in relation to the energy produced (Mackay, 2009b). Separately, each of the four microgeneration schemes produces relatively low levels of energy; however, merging these systems into what is called a hybrid renewable energy system (HRES) is a possible solution (Arul et al., 2015). Consortia of local authorities and energy companies would benefit from identifying where technologies can be delivered together to generate the most energy and create the maximum return on investment.

The HRES would form a number of stations alongside the carriageway with batteries and main connections to pass the energy into either a local network or the national grid. The concept of a dual wind and photovoltaic HRES suggested by Arul et al. (2015) could be adapted to work with several different energy sources. While the introduction of an HRES may be costly to install the increased energy yield means that the payback period is likely to be shorter, making its installation more cost effective than installing standalone systems. This is because an HRES would be able to generate energy in all weather conditions, compared to standalone technologies.

The problem with the national electricity grid is that it cannot store energy (MacKay, 2009a), so it is possible that the energy would need to be stored in batteries locally, so that it could be utilised at times of peak use. While the technology is currently being trialled in countries with weak grids, or no power grids, it is possible that best practice findings could be implemented in the UK and other nations with more stable grids. The HRES approach provides a better solution, as one is not relying on just one means of energy production. The HRES approach is not without its challenges, although many of these can be overcome through forward-thinking energy management, the breaking down of institutional silos and separate funding streams that focus on either energy or transport into innovative techniques in harnessing these energy sources.

\section{Recommendations and conclusion}

The technology review in the section headed 'Energy harnessing technology' highlights that there may be innovative technologies for carriageway pavements that can harness energy, and they are being designed worldwide, but as yet, none of them has made it to the mass market anywhere in the world. One of the primary problems for developing and delivering this technology requires innovation in two different sectors, transportation and energy production, with neither sure who should take the lead. While the intersection of disciplines can be a place for innovation, many factors prevent this becoming reality. One challenge is that at present, transport and energy are treated by academics and practitioners as separate systems. Experts in one field do not feel comfortable undertaking a cross-sectoral view (Hall et al., 2012). Many of the systems are not joined up, such as funding and innovation, and key organisations that would need to be involved may not have experienced working with each other. This paper concludes with a set of practical applications that are required to bring this technology into the mainstream to enable the highway network to be maintained to a high standard and cheap, clean and renewable energy to be harnessed.

\section{Recommendations}

- Develop a body of evidence to identify the best technology, ranking each scheme in terms of stage of delivery (concept, prototype or commercially available), cost, energy produced and payback period. This will provide a basis of where to start developing the technology.

- Identify which government organisation is responsible for delivering investment in this technology and allow them to lead the delivery with the support of other government departments. At present in the UK, this is likely to sit across the Department for Transport, Department for Energy and Department for Communities and Local Government.

- Ensure cross-party buy-in to scheme. Delivering this technology is likely to take decades so any funding needs to be long term and sustained to enable the technology to be delivered.

- Create a set of trials and demonstrations across the country to trial and identify the best technologies in each sector. These trials can be government funded and involve input from universities, businesses, energy providers, utility companies and local authorities.

- Build on findings of the trials to identify what works and where before instigating a mass roll-out of technology.

\section{Conclusion}

Technologies that are able to harness energy are starting to be developed across the world and these have the potential to generate energy and additional finance, if managed correctly, for highway maintenance. The challenge that remains is to identify the best means of bringing this technology to market. Local authorities face significant pressures from both increased usage of the highways due to the increase in vehicles on the network and reductions in maintenance funding moving forward. Generating energy from highways would provide an incentive to allow them to gain some financial benefit from the highway network they manage. This network forms the arteries of the UK economy, so it is essential that it is maintained to a high standard.

For the development of this sector to occur, the national government needs to provide initial investment to trial and test technologies that harness energy from the highway network. By kick-starting interest in this area and identifying it as a government priority area, it is likely that companies will start to invest in the 
research and development of new and innovative technologies while working with local authorities who own and maintain the assets where the technology can be trialled. When the government makes a technical innovation a priority, this generates interest in the sector, as the development of autonomous vehicle technology in the UK has shown (CCAV, 2017). Government investment and support at this early stage will provide a positive step to tackle the trilemma of energy issues facing the country by providing a source of reliable, cheap and renewable energy that will allow the economy to continue to prosper.

\section{Acknowledgements}

The author won the 2017 Wolfson Economics Prize Lightbulb Award for the concept discussed in this paper. Dr Williams' research is funded through the ESRC-funded project PARCOUR (ES/N011333/1).

\section{REFERENCES}

Al Badwawi R, Abusara M and Mallick T (2015) A review of hybrid solar PV and wind energy system. Smart Science 3(3): 127-138

Anthony S (2014) Solar Roadways Passes \$1.4 Million in Crowdfunding: Just Short of the \$56 Trillion Required, But Not Bad for a Crazy Idea. ExtremeTech. See http://www.extremetech.com/extreme/183130-solarroadways-passes-1-4-million-in-crowdfunding-just-short-of-the-56-trillionrequired-but-not-bad-for-a-crazy-idea (accessed 20/04/2018).

Arul P, Ramachandaramurthy V and Rajkumar R (2015) Control strategies for a hybrid renewable energy system: a review. Renewable and Sustainable Energy Reviews 42: 597-608.

BBC (British Broadcasting Corporation) (2017) Councils Make $£ 819 \mathrm{~m}$ from Parking Charges, Says RAC Study. BBC, London, UK. See http://www.bbc.co.uk/news/uk-42132797 (accessed 07/12/2017).

Biello D (2014) Hard Road Ahead for Solar Freakin' Roadways. Scientific American, New York, NY, USA. See https://blogs. scientificamerican.com/observations/hard-road-ahead-for-solar-freakinroadways/ (accessed 20/04/2018).

Butler M (2013) Funding for highways and transportation: a local government perspective. Devolving Major Schemes Seminar, Taunton, UK, 21 November. See http://www.ciht.org.uk/en/media-centre/news. $\mathrm{cfm} /$ devolving-major-schemesseminar-21st-november-2013 (accessed 12/03/201).

CCAV (Centre for Connected and Autonomous Vehicles UK) (2017) Connected and Autonomous Vehicle Research and Development Projects 2017. CCAV, London, UK. See https://assets.publishing. service.gov.uk/government/uploads/system/uploads/attachment_dat a/ file/650444/ccav-research-and-development-projects-2017.pdf (accessed 01/03/2018).

$\mathrm{CIC}$ (Construction Industry Council) (2013) Highways Maintenance Efficiency Programme: Transforming and Improving the Condition of Our Roads. See http://cic.org.uk/admin/resources/highwaysmaintenance-efficiency-programme.pdf (accessed 27/02/2017).

Cohen M (2012) They built that: how a Republican lie turned into an alternate universe. The Guardian, 29 August. See https://www. theguardian.com/commentisfree/2012/aug/29/they-built-thatrepublicans-big-lie (accessed 06/12/2017).

Colas (2017) Wattway by Colas: the Advantages. Colas, Paris, France. See http://www.wattwaybycolas.com/en/ (accessed 19/12/2017).

Coxworth B (2013) Low-cost System Uses Passing Vehicles to Generate Electricity. New Atlas. See http://newatlas.com/vehicle-road-weightelectricity/29990/ (accessed 20/10/2016).

DECC (Department for Energy and Climate Change) (2015) UK Energy in Brief 2015. DECC, London, UK. See https://www.gov.uk/government/ uploads/system/uploads/attachment data/file/611705/building-ourindustrial-strategy-green-paper.pdf (accessed 20/10/2016).

DfT (Department for Transport) (2016) Road Lengths in Great Britain 2015. DfT, London, UK. See https://www.gov.uk/government/ statistics/road-lengths-in-great-britain-2015 (accessed 20/10/2016).

Doward J (2016) Let there be light! Futuristic street lamps tap into the oldest energy source: the sun. The Guardian, 20 March. See https:// www.theguardian.com/environment/2016/mar/20/energy-efficientstreet-lights (accessed 20/10/2016).

Duflon P (2016) Hydrotechnology Extracts Energy from Sewage Water. Water \& Wastewater International, Plymouth, MN, USA. See http:// www.waterworld.com/articles/wwi/print/volume-21/issue-2/regionalfocus/hydro-technology-extracts-energy-from-sewage-water.html (accessed 20/10/2016).

EETS (Energy Environmental Technical Services) (2016) Hybrolight Integrated. EETS, Pontypridd, UK. See http://www.eets.co.uk/ solarandwindpoweredlightingsystems/hybrolight/hybrolightintegratedso larwindpoweredlightingsystem.htm (accessed 20/10/2016).

Graham S (2010) When infrastructures fail. In Disrupted Cities: When Infrastructure Fails (Graham S (ed.)). Routledge, Abingdon, UK, pp. 1-26.

Guosheng T, Xinping D and Jian L (2011) Study of control strategy for hybrid energy storage in win-photovoltaic hybrid streetlight system. IEEE International Workshop on Open-source Software for Scientific Computation, pp. 77-81.

Hall J, Henriques J, Hickford A and Nicholls R (2012) A Fast Track Analysis of strategies for infrastructure provision in Great Britain. Technical Report. Environmental Change Institute, University of Oxford, Oxford, UK.

Hasebe M, Kamikawa Y and Meiarashi S (2006) Thermoelectric generators using solar thermal energy in heated road pavement. International Conference on Thermoelectrics, Vienna, Austria, 6-10 August, pp. 697-700.

HMEP (Highways Maintenance Efficiency Programme) (2017) What Is HMEP? HMEP, London, UK. See http://www.highwaysefficiency.org. uk/about-us.html (accessed 15/12/2017).

HM Government (Her Majesty's Government) (2017) Building Our Industrial Strategy: Green Paper. The Stationery Office, London, UK. See https://www.gov.uk/government/uploads/system/uploads/ attachment_data/file/611705/building-our-industrial-strategy-greenpaper.pdf (accessed 20/10/2017).

Ilahi T, Afroz A, Khan M et al. (2013) Generating electricity through harnessing of kinetic energy using a ramp. International Journal of Modelling and Optimization 3(6): 520-522.

Ingram B (2017) The financial challenges facing local government, financial reform, and the funding of infrastructure by local authorities. Valuing Infrastructure of Cities, Regions and Nations Conference, Leeds, UK, 26-27 April.

Jenkins S (2016) Hinkley, HS2 and Heathrow show May's team are out of their depth. The Guardian, 13 October. See https://www.theguardian. com/commentisfree/2016/oct/13/hinkley-hs2-heathrow-theresa-mayteam-out-of-depth (accessed 20/10/2016).

MacDonald F (2015) The Solar Road in the Netherlands Is Working Even Better Than Expected. Science Alert. See http://www.sciencealert.com/ solar-roads-in-the-netherlands-are-working-even-better-than-expected (accessed 20/10/2016).

MacKay D (2009a) Sustainable Energy - Without the Hot Air. UIT Cambridge, Cambridge, UK.

MacKay D (2009b) Talk of 'kinetic energy plates' is a total waste of energy. The Guardian, 17 June, https://www.theguardian.com/ environment/cif-green/2009/jun/17/renewable-energy-kinetic-road (accessed 09/02/2017).

Met Office (2012) England 1981-2010 Averages. Met Office, Exeter, UK. See http://www.metoffice.gov.uk/climate/uk/averages/19812010/ areal/england.html (accessed 02/02/2017). 
Novo A, Bayon J, Castro-Fresno D and Rodriquez-Hernandez J (2013) Temperature performance of different pervious pavements: rainwater harvesting for energy recovery purposes. Water Resource Management 27: 5003-5016, https://doi.org/10.1007/s11269-013-0270-y.

O'Carroll L (2017) Grayling's claims that the UK can grow more food dismissed as 'tripe'. The Guardian, 16 October. See https://www. theguardian.com/politics/2017/oct/16/chris-graylings-claims-that-ukcan-grow-more-dismissed-as-tripe (accessed 15/12/2017).

Oica (Organisation Internationale des Constructeurs d'Automobiles) (2017) Motorization Worldwide - 2015. Oica, Paris, France. See http:// www.oica.net/category/vehicles-in-use/ (accessed 15/12/2017).

Phillips R (2009a) Speed bumps to get new role as a source of green energy. The Guardian, 8 February. See https://www.theguardian.com/ environment/2009/feb/08/alternative-energy-speed-bumps (accessed 09/02/2017).

Phillips A (2009b) Electro-kinetic Road Ramp Powers Up by Pushing Down. Free Republic. See http://freerepublic.com/focus/f-news/ 2290522/posts (accessed 09/02/2017).

Re Cecconi F, Dejaco M, Pasini D and Maltese S (2016) Asset management in a BIM environment. 16th International Conference on Computing in Civil and Building Engineering, Osaka, Japan, 6-8 July. See http:// www.see.eng.osaka-u.ac.jp/seeit/icccbe2016/Proceedings/Full Papers/ 095-228.pdf (accessed 17/04/2018).

Reuters (2015) French, Finnish Reactor Problems Cast Shadow over UK Nuclear Plan. Reuters, London, UK. See http://uk.reuters.com/article/ edf-britain-idUKL8N15C22S (accessed 20/10/2016).
Rodrigues M, Montañés C and Fueyo N (2010) A method for the assessment of the visual impact caused by the large-scale deployment of renewable-energy facilities. Environmental Impact Assessment Review 30: 240-246.

Ryley T (2010) Travel behaviour response to UK road user charging. Proceedings of the Institution of Civil Engineers - Transport 163(2): 57-62, https://doi.org/10.1680/tran.2010.163.2.57.

Sheehan S (2018) UK Potholes: Government Confirms $£ 100 m$ to Fund Repairs. See https:/www.autocar.co.uk/car-news/industry/uk-potholesgovernment-confirms-\%C2\%A3100m-fund-repairs (accessed 20/04/ 2018).

Solar Roadways (2016) \#OurStory. Solar Roadways, Sandpoint, ID, USA. See http://www.solarroadways.com/about/journey (accessed 20/10/2016). Srinivasan R and Parlikad AK (2017) An approach to value-based infrastructure asset management. Infrastructure Asset Management 4(3): 87-95.

Vaughan A (2017) Explosion at Flamanville nuclear plant in northern France. The Guardian, 9 February. See https://www.theguardian.com/ environment/2017/feb/09/explosion-at-flamanville-nuclear-plant-inwestern-france (accessed 09/02/2017).

Yewon S, Chan Y, Seong H et al. (2016) Road energy harvester designed as a macro-power source using the piezoelectric effect. International Journal of Hydrogen Energy 41: 12563-12568.

Zhou Z, Hu S, Zhang X and Zuo J (2013) Characteristics and application of road absorbing solar energy. Front Energy 7(4): 525-534, https://doi. org/10.1007/s11708-013-0278-2.

\section{How can you contribute?}

To discuss this paper, please submit up to 500 words to the editor at journals@ice.org.uk. Your contribution will be forwarded to the author(s) for a reply and, if considered appropriate by the editorial board, it will be published as a discussion in a future issue of the journal. 